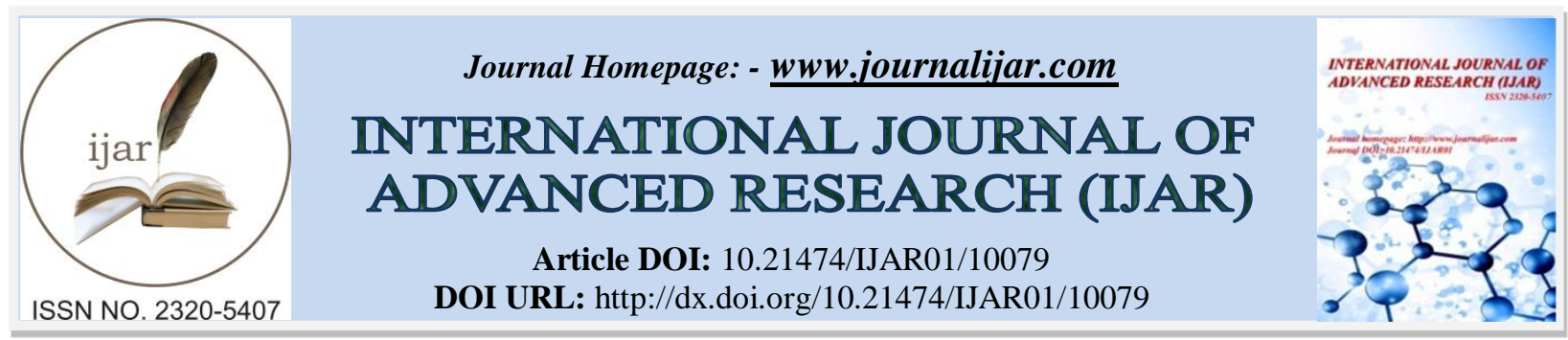

RESEARCH ARTICLE

\title{
CLINICAL STUDY OF HYDATIFORM MOLE IN A TERTIARY HOSPITAL IN GARHWAL, UTTARAKHAND.
}

\author{
Navjyoti Bora $^{1}$, Biant Singh $^{2}$, CMS Rawat $^{3}$ and Haroon Ali Siddiqui ${ }^{4}$ \\ 1. Associate Professor, Dept. Of OBG,VCSGGMSRI, Srinagar, Uttarakhand. \\ 2. Professor, Dept. Of Surgery, VCSGGMSRI., Srinagar, Uttarakhand. \\ 3. Professor,Dept. of Community Medicine,VCSGGMSRI,Srinagar,Uttarakhand. \\ 4. Assistant Professor cum Statistician, Dept. Of Community Medicine, VCSGGMSRI., Srinagar,Uttarakhand.
}

\section{Manuscript Info}

…......................

Manuscript History

Received: 12 September 2019

Final Accepted: 14 October 2019

Published: November 2019

Key words:-

Hydatiform mole, Gestational

Trophoblastic Disease,Partial mole, Suction Evacuation.

\section{Abstract}

Background: Hydatiform is one of the causes of bleeding in early pregnancy.The incidence varies widely throughout the world.The main aim of our study was to determine the incidence and clinical presentation of hydatiform mole in the Garhwal region of Uttarakhand. Methods: Ours is a retrospective study of all the Hydatiform mole cases that were diagnosed in the Obstetrics and Gynecology Department of Veer Chandra Singh Garhwali Government Medical College,Srinagar,Uttarakhand during the period from January 2016 to December 2018.

Results: A total number of 71 cases of Hydatiform mole was diagnosed in our hospital out of the total number of 9864 deliveries during the above period giving the incidence of $0.72 \%$. Vaginal bleeding was the most common symptom present in $91.5 \%$ of the patients.

Conclusion: The incidence of Hydatiform mole in the Garhwal region of Uttarakhand is quite high. Most of the cases here are complete moles which are easily curable by suction evacuation and proper follow up.

Copy Right, IJAR, 2019,. All rights reserved.

\section{Introduction:-}

Hydatidiform Mole is an abnormal condition of the ovum where there is partly degenerative and partly hyperplastic changes in the young chorionic villi". The etymology is derived from Hydatitisia (Greek "a drop of water ") referring to the watery contents of the cysts. There are two types of hydatiform complete and partial based on different histopathological and cytogenetic features.

In general, complete mole have a $46 \mathrm{XX}$ karyotype, the molar chromosomes being derived entirely from father whereas partial mole have either 69 XXY or 69XYY karyotype with one maternal and two paternal haploid chromosomes $^{2}$. Complete moles are characterised by rapidly progressing hyadatiform changes with gross trophoblastic hyperplasia with the absence of blood vessels. On the other hand partial mole shows hyperplasia of syncytiotrophoblast with the presence of blood vessels affecting only a portion of placenta and there is usually the presence of a foetus which generally dies at an early gestational age ${ }^{3}$.

The highest incidence of $\mathrm{H}$ mole is in Indonesia ( 1 in 77 pregnancies ) whereas it is lowest in USA and European countries being about 2 in 1000 pregnancies . Risk factors associated with $\mathrm{H}$ mole includes extremes of maternal 
age, previous $\mathrm{H}$ mole, deficiency of $\beta$-kerotene, animal fat intake and smoking ${ }^{5}$. The Royal College Of Obstetrician And Gynaecologist recommend that suspected molar pregnancies should generally be removed by suction evacuation although hysterectomy is a good option in older patients who are at a risk of developing malignant sequelae. $^{6}$

\section{Materials And Methods:-}

This study was conducted in the Dept. of OBG in VCSGGMSRI, Srinagar, Uttarakhand. It was a retrospective study of all the H. mole cases diagnosed in this institute between January 2016 to December 2018. A total of 71 cases were diagnosed with $\mathrm{H}$. mole during this period and case files of all these cases were sourced from the M.R.D department of our hospital. The diagnosis of $\mathrm{H}$. mole was based on the clinical history and examination, ultrasonography, Serum $\beta-\mathrm{HCG}$ and histopathological reports of the suction evacuation specimen. The maternal age, parity, LMP (for gestational age), educational status, socioeconomic status and history of any prior molar pregnancy were noted.All the symptoms of the patients like vaginal bleeding, abdominal pain and hyperemesis were noted and signs of preeclampsia and thyrotoxicosis were recorded complete medical and obstetrical examination were performed in all patients including vitals, Chest examination and abdominal assessment of fundal height. Vaginal examination was performed in all the cases for state of the cervix and uterine size. The investigations done in all patients include complete blood count, ABO-Rh typing, Serum $\beta$-HCG level, Thyroid profile and Pelvic ultrasound. Chest X-Ray was done in some selected cases where required. Most of the patients were managed by suction and evacuation(S \& E) and the specimen was sent for histopathological examination to the Pathology dept. of our college. Repeat serum $\beta$-HCG level was done for all patients after 45 days. In a few high risk cases, chemotherapy with methotrexate was given.

\section{Statistical Analysis:}

The collected data were entered in Microsoft Excel and were analysed using the software Statistical Package for Social Sciences(SPSS) version 21.0.Descriptive statistical measures such as percentage, frequency etc. were applied.

\section{Result:-}

A total of 9864 patients delivered at VCSGGMSRIduring the period from January 2016 to December 2019. The total number of patients diagnosed with hydatiform mole during this period was 71 giving an incidence of $0.72 \%$. The maximum number of women belonged to the age group of 20-29 years $(36.6 \%)$. The higher number of patients were multiparous $(56.3 \%)$ whereas a very significant number were primigravida $(43.7 \%)$.

In our study, we diagnosed only 2 patients with partial mole $(0.3 \%)$, one patient was a case of invasive mole who underwent hysterectomy and the rest of the cases (99.6\%) were complete hydatiform moles.38 patients (53.5\%) were diagnosed in the first trimester whereas 31 patients were detected in the second trimester. The maximum number of patients $(53.5 \%)$ belonged to the lower socio economic classes. Blood group A belonged to 26 patients whereas only 2 cases with AB blood group were seen.

Table 1:-Maternal Characterstics

\begin{tabular}{|l|c|c|}
\hline Variable & Number & Percentage \\
\hline Age in years & 12 & 16 \\
\hline$<20$ & 26 & 36.6 \\
\hline $20-29$ & 20 & 28.2 \\
\hline $30-39$ & 13 & 18.3 \\
\hline$>40$ & \multicolumn{2}{|c|}{} \\
\hline Parity & 31 & 43.7 \\
\hline 0 & 36 & 50.7 \\
\hline $1-4$ & 4 & 5.6 \\
\hline$>4$ & \multicolumn{2}{|c|}{} \\
\hline Gestational Age & 38 & 53.5 \\
\hline First trimester & 33 & 46.5 \\
\hline Second trimester & \multicolumn{2}{|}{} \\
\hline Socio economic status & \multicolumn{2}{|l|}{} \\
\hline
\end{tabular}




\begin{tabular}{|l|c|c|}
\hline Low & 38 & 53.5 \\
\hline Middle & 24 & 33.5 \\
\hline High & 9 & 12.7 \\
\hline Blood Group & \multicolumn{2}{|c|}{} \\
\hline A & 26 & 36.6 \\
\hline B & 19 & 22.5 \\
\hline AB & 2 & 0.3 \\
\hline O & 4 & 33.8 \\
\hline
\end{tabular}

Vaginal bleeding was overwhelmingly the commonest symptom. As many as 65 patients $(91.5 \%)$ presented with bleeding per vagina. Other notable symptoms were abdominal pain (29.6\%), hyperemesis (16.9\%), passage of grape like vesicles (0.7\%).3 patients (0.4\%) presented with pre eclampsia and 2 patients $(0.3 \%)$ presented with thyrotoxicosis.

The uterine size was larger than the gestational age in 51 patients $(71.8 \%)$ and in only 4 patients $(0.6 \%)$, it was smaller than the gestational age at presentation. Pre treatment $\beta$-HCG was elevated in all the patients. 70 cases were treated by suction evacuation $(98.6 \%)$ whereas only the sole patient with invasive mole underwent hysterectomy. 3 patients $(0.4 \%)$ were given post evacuation chemotherapy with methotrexate.

Table 2:-Clinical Presentation and Management

\begin{tabular}{|l|l|}
\hline Clinical Presentation & Number $(\%)$ \\
\hline Vaginal Bleeding & $65(91.5 \%)$ \\
\hline Abdominal Pain & $21(29.6 \%)$ \\
\hline Hyperemesis & $12(16.9 \%)$ \\
\hline Preeclampsia & $3(6.4 \%)$ \\
\hline Thyrotoxicosis & $2(0.3 \%)$ \\
\hline Passage of villi & $5(0.7 \%)$ \\
\hline Uterine Size & \\
\hline Larger than date & $51(71.8 \%)$ \\
\hline Smaller than date & $4(0.6 \%)$ \\
\hline Compatible with date & $16(22.5 \%)$ \\
\hline Management & \\
\hline Suction Evacuation & $70(98.6)$ \\
\hline Hysterectomy & $1(0.1 \%)$ \\
\hline
\end{tabular}

\section{Discussion:-}

The overall incidence of hydatiform mole in our study was 7.2 per 1000 births or 1 in 134 births. The incidence varies widely throughout the world ranging from 1 in 77 pregnancies in Indonesia to 1 in 357 pregnancies in Nigeria ${ }^{7}$. In India the incidence, according to Shaw's textbook of Gynaecology ranges from 1/160 to 1/500. Even in European countries where the incidence is around 1/2000, the occurrence is significantly higher amongst the Asian population. ${ }^{8}$

In our study the maximum number of women belonged to the age group of 20-29 years(36.8\%) although $28.2 \%$ and $18.3 \%$ cases belonged to the age group of 30-39 years and more than 40 years respectively. A case control study by Le Vecchia et $\mathrm{al}^{9}$ of 132 cases recruited in Lombardy (Northern Italy) showed a clear relation of gestational trophoblastic disease to extremes of maternal age. This study also showed the relation of GTD to advanced paternal age which gives epidemiological support to the cytogenetic evidence of an androgenetic role in the origin of GTD. Several other studies gives the evidence of hydatiform mole to advancing maternal and paternal age ${ }^{10,11,13 .}$ One study showed a clear relationship of $\mathrm{H}$. mole to multiparity which tally with similar studies ${ }^{12}$.

In our study partial moles accounted for only a minuscule number of cases $(0.3 \%)$ which is much lower than most of the other studies ${ }^{14}$. Our finding that blood group A \& O were associated with H.mole was compatible with other 
studies $^{15}$. The main fact that vaginal bleeding was overwhelmingly the most common symptom seen in most other studies.

\section{Conclusion:-}

There is a wide variation in the incidence of Hydatiform mole throughout the world.Although the condition has malignant potential,when detected early and properly managed ,the condition is easily curable.This condition has clear etiological relation to ethnicity,advanced maternal and paternal age and multiparity.The fact that most of the cases in our study were complete moles may have something to do with the fact that most of the cases belonged to the four districts of PauriGarhwal,TehriGarhwal,Rudraprayag and Chamoli districts of the Garhwal region of Uttarakhand.

\section{References:-}

1. PadubidriVG ,Daftary SN, Shaw's textbook of Gyanaecology $15^{\text {th }}$ edition. Elsevier India 2011 pg.- 251-263.

2. Kumar V Pathologic basis of disease. $8^{\text {th }}$ edition. Saunders Elsevier 2010 pg.-1057-58

3. Lawler SD, Fisher RA, Dent JA. Prospective study of complete and partial hydatiform mole. Am J ObstetGyanaecol 1991; 164: 1270-7.

4. Aziz MF, Kompono N, Molgni EM Epidemiology of gestational trophoblastic neoplasia at Dr CiptoMangukusmo Hospital, Jakarta, Indonesia. AdvExp Med Biol1984;176:248-59.

5. Allen SO, Lim AK, Seck MD, Blunt DM, Mitchell AN. Radiology of gestational trophoblastic neoplasia. Clinical Radiology Vol 61 no.4 pp 301-313.

6. Royal College of Obstetricians and Gynaecologists.The Management of Gestational trophoblastic neoplasia.Green Top Guidelines.No 38.London. RCOG;2004.

7. 7.Ocheke AN, Musa J, VamaiAO .Hydatiform mole in Jos, Nigeria. Nigerian Medical Journal 2011;52(4):22326.

8. Tham BW, Everett JE, Tidy JA, Drew D, Hancock BW. Gestational trophoblastic disease in the Asian population of Northern England and North Wales. BJOG 2003;110 (6):555-559.

9. La Vecchia CL, Parazzini F, Deanli A, Age of parents of gestational trophoblastic disease.J Nat'l Cancer Institute 1984;73:639-40.

10. Malhotra S, Jindal UN. Clinical behaviour of hydatiform mole. J Indian Medical Association 1989;87 (7); 157 159.

11. Sebine NJ, Fisher RA, Fostatt M, SeeklNJ,Newlands ES. Risk of recurrent hydatiform mole and subsequent pregnancy outcome following complete or partial hydatiform molar pregnancy. Infer J.ObstetGynaecol 2003; 110:22-26.

12. Muminhodziael L, Bogdanoviae G, Ljuca D, Baboviae A. Epidemiological factors and pathomorphologicalcharacterstics of hydatiform mole. Journal of Health Sciences 2013; 3(2):129-37.

13. Harriet OS. Gestational trophoblastic disease : Epidemiology and trends. ClinObstetGynaecol 2003; 46:541-5.

14. Fisher RA, Hodgen MD, Newlands ES. Familial recurrent hydatiform mole. Journal of Reproductive Medicine 2004;49;595-601.

15. Jafar MR, Abedi D, Fabadi NMT. Gestational trophoblastic disease:a ten year retrospective study Int J FertilSteril 2005;4(1) 1-4. 